\title{
TRANSPARENCY AND RISK SHARING IN INTERNATIONAL TRADE*
}

\author{
by \\ UDO BROLL \\ Technische Universität Dresden \\ BERNHARD ECKWERT \\ University of Bielefeld \\ and \\ KIT PONG WONG \\ University of Hong Kong
}

The paper examines the impact of uncertainty on the decision problem of an international firm. The uncertainty under which the firm decides on home and foreign supply is affected by an information system that conveys public signals about the random spot exchange rate. The transparency in the foreign exchange market is defined by the informativeness of the information system. Our notion of transparency thus proposes an information-based concept of uncertainty. In this setting, we revisit the link between the transparency in the foreign exchange market and the behavior of the international firm. While more transparency may lead to higher or lower domestic sales and foreign exports, we show that the firm's expected profits always go up. The welfare of domestic consumers, by contrast, may increase or decrease with higher transparency in the foreign exchange market.

\section{INTRODUCTION}

The extensive literature on the optimal choice under uncertainty has shown that, in general, the impact of uncertainty on the behavior of risk-averse decision makers is ambiguous. In

\footnotetext{
${ }^{*}$ Correspondence to: Udo Broll, Department of Business and Economics; School of International Studies (ZIS), Technische Universität Dresden, 01062 Dresden, Germany, e-mail: udo.broll@tu-dresden.de (U. Broll)

${ }^{\dagger}$ We thank Pierre Picard (the editor) and two anonymous referees for their helpful comments and suggestions. The usual disclaimer applies.
} 
particular, risk aversion alone is insufficient to assess the marginal impact of uncertainty on production and investment. This ambiguity also applies to the behavior of international firms acting in global markets (Broll and Zilcha, 1992; Kawai and Zilcha, 1986; Wong, 2003).

The issue is further complicated by the fact that the precise meaning of uncertainty, and the right way to model it, is not beyond dispute in the literature. With regard to global markets and international trade, it appears that uncertainty cannot appropriately be captured by standard dispersion concepts such as variances, mean preserving spreads, or other variability orders (Shaked and Shanthikumar, 1994). Our paper therefore proposes an information-based concept of uncertainty and, in this setting, revisits the link between exchange rate risk and firm behavior regarding international trade.

In standard models under price or exchange rate risk, firms acts in an exogenously given uncertain environment. Yet, viewed from a broader perspective, the uncertainty under which production for domestic sales and foreign exports are chosen by firms depends on the available public information in the economy. In our paper we take this important feature into account: taking the prior distribution of the random spot exchange rate as given, we model the uncertainty in an open economy through an information system that conveys signals about the foreign exchange rate. If the information system is more precise, the random spot exchange rate can be assessed more accurately, thereby reducing the uncertainty faced by the firm. ${ }^{1}$

Assuming that risk sharing arrangements exist whereby exporting and importing firms can hedge their exchange rate risk exposure, an exogenous reduction in ex-ante uncertainty (dispersion of the prior distribution) is not the same as a decline of ex-interim uncertainty due to a more precise information system. In fact, the greater reliability of the information signals may change the terms of trade on the risk sharing markets and thus affect firms' trading decisions. Due to this interaction, standard models of international firms do not

\footnotetext{
${ }^{1}$ While we use the notions 'risk' and 'uncertainty' interchangeably, we distinguish between ex-ante uncertainty that refers to the prior distribution of the random spot exchange rate, and ex-interim uncertainty that refers to the distribution conditional on a signal observation.
} 
properly capture the mechanisms through which information-induced changes of uncertainty affect the optimal behavior of firms.

We consider the financial market for foreign currency to be more transparent if it is endowed with a more reliable information system about the risky exchange rate. As argued above, in general higher transparency is not equivalent to a reduction of ex-ante exchange rate uncertainty. Instead, our transparency concept is linked to the reliability of a publicly observable signal that is correlated with the random foreign exchange rate. By conveying some noisy information about the unknown exchange rate, the signal allows the international firm to update its beliefs in a Bayesian manner. The foreign currency market is said to be more transparent if the signal is 'less noisy', i.e., if it conveys more reliable information.

Within this setting our analysis focuses on the activity of a risk-averse international firm, i.e., the firm is selling at home and abroad. To incorporate risk sharing, we assume that the firm has access to a futures market where it can hedge the exchange rate risk conditional on the realization of the public signal. We demonstrate that the impact of more precise information on the firm's ex-ante allocation of production to domestic and foreign markets depends on the marginal revenue and marginal cost functions. In particular, more transparency reduces the firm's expected exports if the domestic marginal revenue and marginal cost functions are convex. In any case, more transparency in the foreign exchange market leads to higher expected profits of the firm. Furthermore our results suggest that transparency is potentially beneficial to all, domestic consumers and the domestic exporting firm.

Before turning to the analysis, let us place our contribution in the broader context of the literature on international trade and investment decisions under uncertainty. By the choice of the transparency criterion, our study is conceptually related to the literature on the modeling and analysis of information structure along the lines of Blackwell (1953). According to Blackwell's approach, an information structure generates random observable signals that are correlated with the unknown future state of the world. The precision of these signals affects the uncertainty under which agents make their choices. This strand 
of literature has analyzed the link between the precision of information structure, optimal individual behavior, and economic welfare both in partial equilibrium settings (Sulganik and Zilcha, 1997; Wakker, 1988) and in general equilibrium settings (Citanna and Villanacci, 2000; Eckwert and Zilcha, 2001, 2003; Green, 1981; Hirshleifer, 1971, 1975).

Our paper is also related to the literature on the optimal choice under uncertainty with incomplete risk sharing arrangements. This literature has investigated in various market settings the role of specific risk factors on the behavior of risk-averse economic agents. By focusing on the intertemporal nature of investment decisions, more recent studies have pointed out that traditional investment rules can be misleading if they fail to properly take into account the opportunity cost of investing (Thijssen et al., 2006). Our paper also builds, of course, on the literature on the modeling of an international firm. This literature describes how a firm acts in global markets (Broll and Zilcha, 1992; Kawai and Zilcha, 1986; Wong, 2003). Typically, the firm is modeled as a risk-averse agent who tries to diversify the risk and charges a risk premium on those risks that cannot be diversified.

In light of the extant literature, the contribution of the current paper is to analyze an international firm's behavior when uncertainty and terms of risk sharing vary with the precision of an information system. In the literature, there are different analytical concepts measuring the degree of information and proposing an order of the underlying information systems (Blackwell, 1953; Kim, 1995; Lehmann, 1988). The notion of transparency used in our study is adopted from the work by Eckwert and Zilcha (2001, 2003). They characterize market transparency by using a criterion that is conceptually related to the literature emerged from the seminal work by Blackwell (1953). ${ }^{2}$ More transparency or more reliable information means that market participants can make better economic decisions. When the information is of public nature, rather than privately owned by an individual, it will be used by all agents. Under such circumstances the information may affect endogenous market mechanisms (Morris and Shin, 2002; Schlee, 2001).

There is a large body of literature which analyzes the welfare effects of public informa-

\footnotetext{
${ }^{2}$ For other concepts of transparency that have been used in the literature, see Heinemann and Illing (2002) and Krebs (2005).
} 
tion. When individuals make decisions in isolation from others, more reliable information is generally beneficial (Blackwell, 1953). Yet, more information can have detrimental effects if the information affects risk sharing arrangements in the economy (Hirshleifer 1971, 1975; Schlee, 2001) or if agents interact strategically using private information and public information simultaneously. In this paper we abstract from informational asymmetries but we allow for some risk sharing through a competitive currency futures market. While market transparency does not affect the risk premium on this market, it does have implications for the amount of risk that will be shared in equilibrium.

The rest of the paper is organized as follows. Section 2 develops a model of an international firm under exchange rate uncertainty. In section 3 , we introduce the concept of information-based risk that underlies the analysis. Section 4 derives the main results. In section 5 , we present a numerical example in order to illustrate and to quantify the impact of transparency on the expected level of output. Section 6 concludes.

\section{The Model}

Consider an international firm that makes decisions under exchange rate uncertainty. There is one period with two dates, indexed by $t=0$ and 1 . The firm is risk averse and possesses a von-Neumann-Morgenstern utility function, $u(\pi)$, defined over its home currency profit, $\pi$, at $t=1$, where $u^{\prime}(\pi)>0$ and $u^{\prime \prime}(\pi)<0$ for all $\pi>0$.

At $t=0$, the firm produces a single homogeneous good in the home country according to a known cost function, $c(q)$, where $q \geq 0$ is the level of output, $c(0)=c^{\prime}(0)=0$, and $c^{\prime}(q)>0$ and $c^{\prime \prime}(q)>0$ for all $q>0 .^{3}$ The firm also has to decide how to allocate its entire output, $q$, between domestic sales and foreign exports. Specifically, the firm commits to selling $s$ units of the good in the home market and exporting the rest, $x=q-s$, to a foreign country at $t=1$, where $0 \leq s \leq q$.

The firm enjoys some monopoly power in the home market wherein it faces a known

\footnotetext{
${ }^{3}$ The strict convexity of the cost function reflects the fact that the firm's production technology exhibits decreasing returns to scale.
} 
revenue function, $r(s)$, denominated in the home currency with $r(0)=0$, and $r^{\prime}(s)>0$ and $r^{\prime \prime}(s)<0$ for all $s \geq 0$. The firm, however, is a price taker in the foreign market wherein it sells at a fixed per unit price, $p>0$, denominated in the foreign currency. ${ }^{4}$ Due to the segmentation of the home and foreign markets, arbitrage transactions are either impossible or unprofitable, thereby invalidating the law of one price. ${ }^{5}$

We model the exchange rate uncertainty by a random variable, $\tilde{e}$, that denotes the spot exchange rate at $t=1$ and is expressed in units of the home currency per unit of the foreign currency. ${ }^{6}$ The realization of $\tilde{e}$ is not known until $t=1$. The firm, however, holds a prior belief that $\tilde{e}$ is distributed according to a probability density function, $f(e)$, over support $[\underline{e}, \bar{e}]$ at $t=0$, where $0<\underline{e}<\bar{e}$.

There is a public signal, $\tilde{y}$, released by the government or the central bank at $t=0$ before the firm makes any decisions. Let $n(y)$ be the prior probability density function of $\tilde{y}$ over support $[\underline{y}, \bar{y}]$, where $\underline{y}<\bar{y}$. The signal, $\tilde{y}$, is correlated with the random spot exchange rate, $\tilde{e}$, and thus contains valuable information about $\tilde{e}$. The firm updates its belief in a Bayesian manner. Let $\nu(e \mid y)$ be the posterior probability density function of $\tilde{e}$ conditioned on $\tilde{y}=y$ over support $[\underline{e}, \bar{e}]$. After observing the realized public signal, $y$, the firm makes its decisions based on $\nu(e \mid y)$ at $t=0$.

The firm has access to a foreign exchange futures market for hedging purposes. The foreign exchange futures market opens at $t=0$ after the public signal has been revealed. Let $e_{f}$ be the futures exchange rate that is determined at $t=0$ and is expressed in units of the home currency per unit of the foreign currency. We assume that risk-neutral arbitrageurs are active in the foreign exchange futures market so that

$$
e_{f}=\int_{\underline{e}}^{\bar{e}} e \nu(e \mid y) \mathrm{d} e
$$

\footnotetext{
${ }^{4}$ If the firm also has market power in the foreign country, the concavity of the marginal cost function continues to be sufficient for a positive impact of transparency on average output (cf. Proposition 1). Yet, this condition is no longer necessary. In fact, even with convex marginal production costs more transparency may raise the average output level. Similarly, convexity of the marginal cost function constitutes a necessary, but no longer sufficient condition for an inverse link between transparency and average output.

${ }^{5}$ Engel and Rogers $(1996,2001)$ and Parsley and Wei (1996) provide supportive evidence that arbitrage transactions among national markets are indeed imperfect.

${ }^{6}$ Throughout the paper, random variables have a tilde $(\sim)$ while their realizations do not.
} 
for all $y \in[\underline{y}, \bar{y}]$. It is evident from Eq. (1) that the unbiased futures exchange rate, $e_{f}$, is a linear function of the posterior probability density function, $\nu(e \mid y)$.

The firm's profit at $t=1$, denominated in the home currency, is given by

$$
\tilde{\pi}=r(s)+\tilde{e} p x-c(s+x)+\left(e_{f}-\tilde{e}\right) h,
$$

where $h$ is the number of the unbiased foreign exchange futures contracts sold (purchased if negative) by the firm at $t=0$. Conditional on the realized public signal, $y$, the firm's decision problem at $t=0$ is to choose a level of domestic sales, $s$, a level of foreign exports, $x$, and a futures position, $h$, so as to maximize the expected utility of its random home currency profit at $t=1$ :

$$
\max _{s \geq 0, x \geq 0, h} \int_{\underline{e}}^{\bar{e}} u\left[r(s)+e p x-c(s+x)+\left(e_{f}-e\right) h\right] \nu(e \mid y) \mathrm{d} e .
$$

Figure 1 depicts how the sequence of events unfolds in the model.

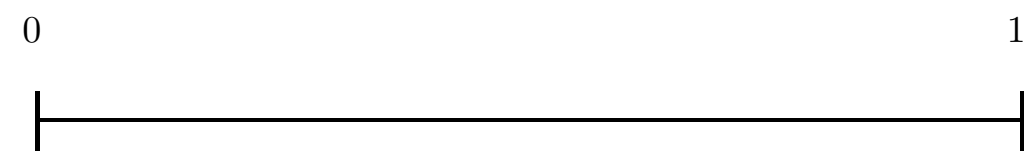

The public signal is observed.

The spot exchange rate is realized.

The firm makes its production, sales allocation, and hedging decisions.

The firm sells its output and settles its futures position.

Figure 1. Time Line

The first-order conditions for program (3) are given by

$$
\begin{aligned}
& \int_{\underline{e}}^{\bar{e}} u^{\prime}\left[r\left(s^{*}\right)+e p x^{*}-c\left(s^{*}+x^{*}\right)+\left(e_{f}-e\right) h^{*}\right]\left[r^{\prime}\left(s^{*}\right)-c^{\prime}\left(s^{*}+x^{*}\right)\right] \nu(e \mid y) \mathrm{d} e=0, \\
& \int_{\underline{e}}^{\bar{e}} u^{\prime}\left[r\left(s^{*}\right)+e p x^{*}-c\left(s^{*}+x^{*}\right)+\left(e_{f}-e\right) h^{*}\right]\left[e p-c^{\prime}\left(s^{*}+x^{*}\right)\right] \nu(e \mid y) \mathrm{d} e=0,
\end{aligned}
$$


and

$$
\int_{\underline{e}}^{\bar{e}} u^{\prime}\left[r\left(s^{*}\right)+e p x^{*}-c\left(s^{*}+x^{*}\right)+\left(e_{f}-e\right) h^{*}\right]\left(e_{f}-e\right) \nu(e \mid y) \mathrm{d} e=0,
$$

where an asterisk indicates an optimal level. If $h^{*}=p x^{*}$, the firm's home currency profit at $t=1$ becomes $r\left(s^{*}\right)+e_{f} p x^{*}-c\left(s^{*}+x^{*}\right)$, which does not depend on $\tilde{e}$. It then follows from Eq. (1) that Eq. (6) is satisfied at $h^{*}=p x^{*}$. In this case, Eqs. (4) and (5) reduce to

$$
r^{\prime}\left(s^{*}\right)-c^{\prime}\left(s^{*}+x^{*}\right)=0
$$

and

$$
e_{f} p-c^{\prime}\left(s^{*}+x^{*}\right)=0
$$

Hence, we establish the well-known separation and full-hedging results in our model (Broll and Zilcha, 1992; Kawai and Zilcha, 1986; Wong, 2003).

\section{Transparency ANd Information Systems}

We follow Eckwert and Zilcha $(2001,2003)$ to define the transparency in the foreign exchange market by the informativeness of the signal, $\tilde{y}$, that is publicly observable at $t=0$. In practice, the signal may represent the projection of an expert (the central bank or a research institution) on the future path of the spot exchange rate. The noisiness of the signal reflects forecasting errors. The signal may also be the information about other economic variables such as the fiscal and monetary policy and the foreign exchange position of the central bank. The noisiness of the signal comes from the imprecise relation between those economic variables and the prevailing spot exchange rate.

The informativeness of the signal depends on the information system within which signals can be interpreted. An information system, denoted by $g$, specifies a set of conditional probability density functions of $\tilde{y},\{g(y \mid e): e \in[\underline{e}, \bar{e}]\}$, over support $[\underline{y}, \bar{y}]$. This set of conditional probability density functions, according to which signals are generated for a given 
spot exchange rate, is common knowledge. The firm acts in a Bayesian manner to revise its expectations and maximizes its expected utility on the basis of the updated belief.

Given the information system, $g$, we can write the prior probability density function of $\tilde{y}$ as

$$
n(y)=\int_{\underline{e}}^{\bar{e}} g(y \mid e) f(e) \mathrm{d} e,
$$

for all $y \in[\underline{y}, \bar{y}]$. By Bayes' rule, we can use Eq. (9) to write the posterior probability density function of $\tilde{e}$ conditioned on $\tilde{y}=y$ as

$$
\nu(e \mid y)=\frac{g(y \mid e) f(e)}{n(y)}
$$

for all $y \in[\underline{y}, \bar{y}]$. The following criterion that ranks different information systems according to their informational contents is adopted from Blackwell (1953).

Definition 1. Let $^{1}$ and $g^{2}$ be two information systems. $g^{1}$ is said to be more informative than $g^{2}$ if there exists an integrable function, $\lambda\left(y^{\prime}, y\right):[\underline{y}, \bar{y}] \times[\underline{y}, \bar{y}] \rightarrow \mathbb{R}_{+}$, such that

$$
\int_{\underline{y}}^{\bar{y}} \lambda\left(y^{\prime}, y\right) \mathrm{d} y^{\prime}=1
$$

holds for all $y \in[\underline{y}, \bar{y}]$, and

$$
g^{2}\left(y^{\prime} \mid e\right)=\int_{\underline{y}}^{\bar{y}} g^{1}(y \mid e) \lambda\left(y^{\prime}, y\right) \mathrm{d} y,
$$

holds for all $e \in[\underline{e}, \bar{e}]$.

According to Definition $1, g^{1}$ is more informative than $g^{2}$ if the latter can be obtained from the former through a process of randomization. Eq. (11) implies that $\lambda\left(y^{\prime}, y\right)$ can be interpreted as a probability density function of $\tilde{y}^{\prime}$ over support $[\underline{y}, \bar{y}]$ for a given value of $y$. Eq. (12) describes the course of the randomization process that transforms the original signal, $\tilde{y}$, into a new signal, $\tilde{y}^{\prime}$, via the probability density function, $\lambda\left(y^{\prime}, y\right)$. If the $y^{\prime}$-values are generated in this way, the information system, $g^{2}$, can be interpreted as being obtained from the information system, $g^{1}$, by adding random noise. Since $\lambda\left(y^{\prime}, y\right)$ does not depend 
on $e$, the signals under $g^{2}$ contain no new information about the realization of $\tilde{e}$ that has not been conveyed by the signals under $g^{1}$. As a consequence, the conditional exchange rate uncertainty under $g^{1}$ must be lower than that under $g^{2}$.

As an example, we assume that the random spot exchange rate, $\tilde{e}$, takes on one of two possible values, $e_{1}$ and $e_{2}$, such that $0<e_{1}<e_{2}$ and $f\left(e_{1}\right)=f\left(e_{2}\right)=1 / 2$. The public signal, $\tilde{y}$, takes on one of two possible values, $y_{1}$ and $y_{2}$, with $y_{1}<y_{2}$. The information system, $g$, is defined by a pair of conditional probability density functions of $\tilde{y}$ such that $g\left(y_{1} \mid e_{1}\right)=g\left(y_{2} \mid e_{2}\right)=\gamma$ and $g\left(y_{1} \mid e_{2}\right)=g\left(y_{2} \mid e_{1}\right)=1-\gamma$, where $\gamma \in[1 / 2,1]$ is a constant. The prior probability density function of $\tilde{y}$ is given by $n(y)=g\left(y \mid e_{1}\right) f\left(e_{1}\right)+g\left(y \mid e_{2}\right) f\left(e_{2}\right)=1 / 2$ for $y \in\left\{y_{1}, y_{2}\right\}$. Let $g^{1}$ and $g^{2}$ be the information systems when $\gamma=1$ and $\gamma=1 / 2$, respectively. Under $g^{1}$, we have $e_{f}=e_{i}$ when the public signal is $y_{i}$ for $i=1$ and 2 . There is no conditional exchange rate uncertainty so that $g^{1}$ signifies a fully informative information system. On the other hand, under $g^{2}$, we have $e_{f}=\left(e_{1}+e_{2}\right) / 2$ irrespective of the signal. The conditional exchange rate uncertainty remains the same as the prior so that $g^{2}$ signifies a completely uninformative information system.

Consider the function, $\lambda\left(y^{\prime}, y\right)$, such that $\lambda\left(y_{1}, y\right)=\lambda\left(y_{2}, y\right)=1 / 2$ for $y \in\left\{y_{1}, y_{2}\right\}$. Then, we have $g^{2}\left(y^{\prime} \mid e_{1}\right)=g^{1}\left(y_{1} \mid e_{1}\right) \lambda\left(y^{\prime}, y_{1}\right)+g^{1}\left(y_{2} \mid e_{1}\right) \lambda\left(y^{\prime}, y_{2}\right)=1 / 2$, and $g^{2}\left(y^{\prime} \mid e_{2}\right)=$ $g^{1}\left(y_{1} \mid e_{2}\right) \lambda\left(y^{\prime}, y_{1}\right)+g^{1}\left(y_{2} \mid e_{2}\right) \lambda\left(y^{\prime}, y_{2}\right)=1 / 2$ for $y^{\prime} \in\left\{y_{1}, y_{2}\right\}$. It follows immediately from Definition 1 that $g^{1}$ is more informative than $g^{2}$. Since $g^{1}$ is a fully informative information system while $g^{2}$ is a completely uninformative information system, $g^{1}$ is indeed more informative than $g^{2}$.

Our notion of transparency in the foreign exchange market is based on the informational content of the signal. A signal that conveys information about the random spot exchange rate affects the conditional exchange rate uncertainty in the economy. We characterize the foreign exchange market as more transparent if the signal conveys more information about $\tilde{e}$. Thus, higher market transparency implies that the conditional exchange rate uncertainty is reduced through the dissemination of more reliable information, which leads to the following definition. 
Definition 2. Let $g^{1}$ and $g^{2}$ be two information systems for the random spot exchange rate, e. The foreign exchange market is said to be more transparent under $g^{1}$ than under $g^{2}$ if $g^{1}$ is more informative than $g^{2}$.

It follows from Definitions 1 and 2 that higher transparency reduces the dispersion of the conditional spot exchange rate distribution. However, higher transparency involves no bias as it does not affect the unconditional expected spot exchange rate. To see this, we use Eq. (12) to get

$$
\int_{\underline{y}}^{\bar{y}} g^{2}\left(y^{\prime} \mid e\right) \mathrm{d} y^{\prime}=\int_{\underline{y}}^{\bar{y}} \int_{\underline{y}}^{\bar{y}} g^{1}(y \mid e) \lambda\left(y^{\prime}, y\right) \mathrm{d} y \mathrm{~d} y^{\prime}=\int_{\underline{y}}^{\bar{y}} g^{1}(y \mid e) \mathrm{d} y,
$$

where the second equality follows from Eq. (11). Using Eq. (1), we have the unconditional expected spot exchange rate:

$$
\int_{\underline{y}}^{\bar{y}}\left[\int_{\underline{e}}^{\bar{e}} e \nu(e \mid y) \mathrm{d} e\right] n(y) \mathrm{d} y=\int_{\underline{e}}^{\bar{e}} e f(e)\left[\int_{\underline{y}}^{\bar{y}} g(y \mid e) \mathrm{d} y\right] \mathrm{d} e,
$$

where the equality follows from Eq. (10). It then follows from Eqs. (13) and (14) that the unconditional expected spot exchange rate is invariant to different information systems.

The following lemma formulates an alternative transparency criterion that is in accord with Definition 2. It provides a convenient practical tool for the analysis of our model.

Lemma 1. The foreign exchange market is more transparent under the information system, $g^{1}$, than under the information system, $g^{2}$, if, and only if,

$$
\int_{\underline{y}}^{\bar{y}} F\left[\nu^{1}(\cdot \mid y)\right] n^{1}(y) \mathrm{d} y>\int_{\underline{y}}^{\bar{y}} F\left[\nu^{2}(\cdot \mid y)\right] n^{2}(y) \mathrm{d} y,
$$

for every strictly convex function, $F(\cdot)$, defined on the set of posterior probability density functions of ẽ over support $[\underline{e}, \bar{e}]$.

A formal proof of Lemma 1 can be found in Kihlstrom (1984). Note that $\nu^{1}(\cdot \mid y)$ and $\nu^{2}(\cdot \mid y)$ are the posterior beliefs under the two information systems. Thus, Lemma 1 implies that more transparency raises the expectation of any strictly convex function of the posterior 
belief. For strictly concave functions, inequality (15) is reversed. It is worthwhile pointing out that the convexity of $F(\cdot)$ in Lemma 1 is defined on the posterior belief and not on the realization of the signal. As such, higher transparency neither implies nor is implied by the second-order stochastic dominance of the signal distribution.

\section{International Allocations and Welfare Implications}

In this section, we perform the comparative statics with respect to the futures exchange rate, $e_{f}$. To this end, we write Eqs. (7) and (8) as

$$
r^{\prime}\left[s^{*}\left(e_{f}\right)\right]-c^{\prime}\left[s^{*}\left(e_{f}\right)+x^{*}\left(e_{f}\right)\right]=0,
$$

and

$$
e_{f} p-c^{\prime}\left[s^{*}\left(e_{f}\right)+x^{*}\left(e_{f}\right)\right]=0 .
$$

Differentiating Eqs. (16) and (17) with respect to $e_{f}$ yields

$$
\begin{aligned}
& s^{* \prime}\left(e_{f}\right)=\frac{p}{r^{\prime \prime}\left[s^{*}\left(e_{f}\right)\right]}<0, \\
& x^{* \prime}\left(e_{f}\right)=\frac{p}{c^{\prime \prime}\left[s^{*}\left(e_{f}\right)+x^{*}\left(e_{f}\right)\right]}-\frac{p}{r^{\prime \prime}\left[s^{*}\left(e_{f}\right)\right]}>0,
\end{aligned}
$$

and

$$
q^{* \prime}\left(e_{f}\right)=s^{* \prime}\left(e_{f}\right)+x^{* \prime}\left(e_{f}\right)=\frac{p}{c^{\prime \prime}\left[q^{*}\left(e_{f}\right)\right]}>0
$$

Thus, an increase in the futures exchange rate, $e_{f}$, increases the levels of exports and output but decreases the amount of domestic sales.

Denote $\overline{q^{*}}$ as the expected level of output. Then, we have

$$
\overline{q^{*}}=\int_{\underline{y}}^{\bar{y}} q^{*}\left(e_{f}\right) n(y) \mathrm{d} y .
$$


Proposition 1 characterizes the link between the expected level of output and the transparency in the foreign exchange market by imposing restrictions on the cost function, $c(q)$.

Proposition 1. More transparency in the foreign exchange market leads to a higher (lower) expected level of output if, and only if, the marginal cost function, $c^{\prime}(q)$, is strictly concave (convex).

Proof. It is evident from Eq. (1) that $e_{f}$ is a linear function of the posterior probability density function, $\nu(e \mid y)$. Lemma 1 and Eq. (21) imply that the average level of output increases (decreases) with more transparency in the foreign exchange market if, and only if, $q^{*}\left(e_{f}\right)$ is strictly convex (concave) in $e_{f}$. Differentiating Eq. (20) with respect to $e_{f}$ yields

$$
q^{* \prime \prime}\left(e_{f}\right)=-\frac{p^{2} c^{\prime \prime \prime}\left[q^{*}\left(e_{f}\right)\right]}{c^{\prime \prime}\left[q^{*}\left(e_{f}\right)\right]^{3}},
$$

where we have used Eq. (20). The desired results follow immediately from Eq. (22).

The intuition behind Proposition 1 is as follows. With more transparency, good signals lead to an increase in output, while bad signals lead to a decrease in output. When the marginal cost is increasing at a decreasing (an increasing) rate, the increase in output in response to a good signal is larger (smaller) than the decrease in output in response to a bad signal. As such, the average level of output goes up (down) when the marginal cost function is strictly concave (convex).

The above result depends on the third derivative of the cost function. To gain further insight into this restriction, we consider the firm that has a Cobb-Douglas production function, $q(K, L)=K^{\alpha} L^{\beta}$, where $K$ is the capital stock, $L$ is the labor input, and $\alpha$ and $\beta$ are positive constants with $\alpha+\beta<1$ so that the firm's production technology exhibits decreasing returns to scale. If the unit cost of capital and that of labor are $\rho$ and $w$, respectively, it is easily verified the firm's cost function, $c(q)$, is given by

$$
c(q)=(\alpha+\beta)\left(\frac{\rho}{\alpha}\right)^{\alpha /(\alpha+\beta)}\left(\frac{w}{\beta}\right)^{\beta /(\alpha+\beta)} q^{1 /(\alpha+\beta)} .
$$

Eq. (23) implies that $c^{\prime}(q)$ is strictly concave or convex, depending on whether $\alpha+\beta$ is 
larger or smaller than $1 / 2$, respectively. In this example, more transparency in the foreign exchange market reduces or enhances the expected level of output, depending on whether the firm's production technology exhibits sufficient decreasing returns to scale or not.

Denote $\overline{s^{*}}$ as the expected level of domestic sales. Then, we have

$$
\overline{s^{*}}=\int_{\underline{y}}^{\bar{y}} s^{*}\left(e_{f}\right) n(y) \mathrm{d} y .
$$

Proposition 2 characterizes the link between the expected level of domestic sales and the transparency in the foreign exchange market by imposing restrictions on the revenue function, $r(s)$.

Proposition 2. More transparency in the foreign exchange market leads to a higher (lower) expected level of domestic sales if, and only if, the marginal revenue function, $r^{\prime}(s)$, is strictly convex (concave).

Proof. By Eq. (1), $e_{f}$ is linear in the posterior belief, $\nu(\cdot \mid y)$. It follows from Lemma 1 and Eq. (24 that the expected level of domestic sales increases (decreases) with more transparency if, and only if, $s^{*}\left(e_{f}\right)$ is strictly convex (concave) in $e_{f}$. Differentiating Eq. (18) with respect to $e_{f}$ yields

$$
s^{* \prime \prime}\left(e_{f}\right)=-\frac{p^{2} r^{\prime \prime \prime}\left[s^{*}\left(e_{f}\right)\right]}{r^{\prime \prime}\left[s^{*}\left(e_{f}\right)\right]^{3}} .
$$

The desired results follow immediately from Eq. (25).

Since $x=q-s$, the expected level of foreign exports is given by

$$
\overline{x^{*}}=\int_{\underline{y}}^{\bar{y}} x^{*}\left(e_{f}\right) n(y) \mathrm{d} y=\overline{q^{*}}-\overline{s^{*}} .
$$

Applying the results from Propositions 1 and 2 to Eq. (26), we establish the following corollary.

Corollary 1. More transparency in the foreign exchange market leads to a higher (lower) expected level of foreign exports if both the marginal revenue function, $r^{\prime}(s)$, and the marginal cost function, $c^{\prime}(q)$, are strictly concave (convex). 
Since the full-hedging theorem holds in that the firm's optimal futures position is a full-hedge, i.e., $h^{*}=p x^{*}$, we have the following corollary.

Corollary 2. More transparency in the foreign exchange market leads to a higher (lower) expected volume of hedging if both the marginal revenue function, $r^{\prime}(s)$, and the marginal cost function, $c^{\prime}(q)$, are strictly concave (convex).

While the effects of more transparency on production, sales allocation, and hedging decisions depend crucially on the parametric specifications of the model, we show in the following proposition that more transparency unambiguously raises the firm's expected profit.

Proposition 3. More transparency in the foreign exchange market always leads to an increase in the expected profit of the firm.

Proof. Proceeding along the same lines as in the proof of Proposition 1, we need to show that

$$
\pi^{*}\left(e_{f}\right)=r\left[s^{*}\left(e_{f}\right)\right]+e_{f} p x^{*}\left(e_{f}\right)-c\left[s^{*}\left(e_{f}\right)+x^{*}\left(e_{f}\right)\right]
$$

is strictly convex in $e_{f}$. Differentiating Eq. (27) with respect to $e_{f}$ yields

$$
\pi^{* \prime}\left(e_{f}\right)=p x^{*}\left(e_{f}\right)>0
$$

where we have used Eqs. (7) and (8). Differentiating Eq. (28) again yields

$$
\pi^{* \prime \prime}\left(e_{f}\right)=p x^{* \prime}\left(e_{f}\right)>0
$$

where we have used Eq. (19). The claim then follows from Eq. (29).

To see the intuition for Proposition 3, we have

$$
\pi^{* \prime}\left(e_{f}\right)=\frac{\partial \pi^{*}\left(e_{f}\right)}{\partial s^{*}\left(e_{f}\right)} s^{* \prime}+\frac{\partial \pi^{*}\left(e_{f}\right)}{\partial x^{*}\left(e_{f}\right)} x^{* \prime}\left(e_{f}\right)+\frac{\partial \pi^{*}\left(e_{f}\right)}{\partial e_{f}}=\frac{\partial \pi^{*}\left(e_{f}\right)}{\partial e_{f}}=p x^{*}\left(e_{f}\right)
$$


An increase in $e_{f}$ has a first-order effect on the firm's maximum profit through the export revenues, $p x^{*}\left(e_{f}\right)$. Since the firm exports more when $e_{f}$ increases, this first-order effect on $\pi^{*}\left(e_{f}\right)$ is stronger for a larger value of $e_{f}$ and weaker for a lower value of $e_{f}$. As a result, the firm's profit function is convex in $e_{f}$. A more transparent foreign exchange market makes $e_{f}$ more sensitive to changes in the public signal, thereby leading to higher expected profits.

Finally, we turn to the welfare implication of more transparency in the foreign exchange market for domestic consumers. Let $D(s)$ be the strictly decreasing inverse demand for the homogeneous good in the home market, where $s$ is the amount of domestic sales. Since $r(s)=D(s) s$, the domestic consumers' surplus can be written as

$$
C S\left(e_{f}\right)=\int_{0}^{s^{*}\left(e_{f}\right)} D(s) \mathrm{d} s-D\left[s^{*}\left(e_{f}\right)\right] s^{*}\left(e_{f}\right) .
$$

We measure consumer welfare by the expected level of the domestic consumers' surplus:

$$
\overline{C S}=\int_{\underline{y}}^{\bar{y}} C S\left(e_{f}\right) n(y) \mathrm{d} y .
$$

The following proposition provides sufficient conditions under which more transparency in the foreign exchange market promotes consumer welfare.

Proposition 4. More transparency in the foreign exchange market leads to a higher expected level of the domestic consumers' surplus if the inverse demand function, $D(s)$, is weakly concave and the marginal revenue function, $r^{\prime}(s)$, is weakly convex.

Proof. Proceeding along the same lines as in the proof of Proposition 1, we need to show that $C S\left(e_{f}\right)$ is strictly convex in $e_{f}$. Using Leibniz's rule to differentiate Eq. (31) with respect to $e_{f}$ yields

$$
C S^{\prime}\left(e_{f}\right)=-\frac{p D^{\prime}\left[s^{*}\left(e_{f}\right)\right] s^{*}\left(e_{f}\right)}{r^{\prime \prime}\left[s^{*}\left(e_{f}\right)\right]}
$$

where we have used Eq. (18). Differentiating Eq. (33) with respect to $e_{f}$ yields

$$
C S^{\prime \prime}\left(e_{f}\right)=-\frac{p^{2} D^{\prime}\left[s^{*}\left(e_{f}\right)\right]}{r^{\prime \prime}\left[s^{*}\left(e_{f}\right)\right]^{2}}\left\{1-s^{*}\left(e_{f}\right) \frac{r^{\prime \prime \prime}\left[s^{*}\left(e_{f}\right)\right]}{r^{\prime \prime}\left[s^{*}\left(e_{f}\right)\right]}+s^{*}\left(e_{f}\right) \frac{D^{\prime \prime}\left[s^{*}\left(e_{f}\right)\right]}{D^{\prime}\left[s^{*}\left(e_{f}\right)\right]}\right\}
$$


The claim then follows from Eq. (34).

Propositions 3 and 4 suggest that more transparency in the foreign exchange market may lead to a Pareto improvement in that both the international firm and domestic consumers are made better off. ${ }^{7}$ This findings are in stark contrast to the more pessimistic assessments of the value of information in risk sharing markets derived by Eckwert and Zilcha (2003) and Schlee (2001).

\section{A Numerical Example}

In this section, we consider the two-state example as described in Section 3. The random spot exchange rate, $\tilde{e}$, takes on one of two possible values, $e_{1}$ and $e_{2}$, such that $0<e_{1}<e_{2}$ and $f\left(e_{1}\right)=f\left(e_{2}\right)=1 / 2$. The public signal, $\tilde{y}$, takes on one of two possible values, $y_{1}$ and $y_{2}$, with $y_{1}<y_{2}$. The information system, $g$, is defined by $g\left(y_{1} \mid e_{1}\right)=g\left(y_{2} \mid e_{2}\right)=\gamma$ and $g\left(y_{1} \mid e_{2}\right)=g\left(y_{2} \mid e_{1}\right)=1-\gamma$, where $\gamma \in[1 / 2,1]$ measures the informativeness of $g$. The pair of the conditional probability density functions of $\tilde{e}$ are therefore given by $\nu\left(e_{1} \mid y_{1}\right)=$ $\nu\left(e_{2} \mid y_{2}\right)=\gamma$ and $\nu\left(e_{2} \mid y_{1}\right)=\nu\left(e_{1} \mid y_{2}\right)=1-\gamma$. It follows that $e_{f}\left(y_{1}\right)=e_{1}+\left(e_{2}-e_{1}\right)(1-\gamma)$ and $e_{f}\left(y_{2}\right)=e_{1}+\left(e_{2}-e_{1}\right) \gamma$.

We assume that the firm's cost function is given by $c(q)=q^{\sigma} / \sigma$, where $\sigma$ is a constant greater than unity. Solving Eq. (17) yields $q^{*}\left(e_{f}\right)=\left(e_{f} p\right)^{1 /(\sigma-1)}$. Eq. (21) becomes

$$
\overline{q^{*}}=\frac{p^{1 /(\sigma-1)}}{2}\left\{\left[e_{1}+\left(e_{2}-e_{1}\right)(1-\gamma)\right]^{1 /(\sigma-1)}+\left[e_{1}+\left(e_{2}-e_{1}\right) \gamma\right]^{1 /(\sigma-1)}\right\}
$$

We compare the expected level of output when the foreign exchange market is fully transparent (i.e., $\gamma=1$ ), and that when the foreign exchange market is completely opaque (i.e., $\gamma=1 / 2$ ). Setting $\gamma=1$ in Eq. (35) yields

$$
{\overline{q^{*}}}_{\text {full }}=\frac{p^{1 /(\sigma-1)}}{2}\left[e_{1}^{1 /(\sigma-1)}+e_{2}^{1 /(\sigma-1)}\right]
$$

\footnotetext{
${ }^{7}$ For example, more transparency in the foreign exchange market improves consumer welfare should the inverse demand function be linear.
} 
in the transparent foreign exchange market. Setting $\gamma=1 / 2$ in Eq. (35) yields

$$
{\overline{q^{*}}}_{n u l l}=p^{1 /(\sigma-1)}\left(\frac{e_{1}+e_{2}}{2}\right)^{1 /(\sigma-1)}
$$

in the opaque foreign exchange market. Since the function $k(a)=a^{1 /(\sigma-1)}$ is strictly convex (concave) if $\sigma<(>) 2$, it follows from Jensen's inequality and Eqs. (36) and (37) that ${\overline{q^{*}}}_{\text {full }}>(<){\overline{q^{*}}}_{\text {null }}$. These results are consistent with those of Proposition 1 since $c^{\prime}(q)$ is strictly concave (convex) if $\sigma<(>) 2$.

To quantify the effect of more transparency on output, we set $e_{1}=5, e_{2}=15$, and $\sigma=11 / 10$. In this case, ${\overline{q^{*}}}_{\text {full }} /{\overline{q^{*}}}_{\text {null }}=28.8$. Thus, the expected level of output in the transparent foreign exchange market is almost 28 times higher than that in the opaque foreign exchange market. If $\sigma$ takes values exceeding 2 , then ${\overline{q^{*}}}_{\text {full }} /{\overline{q^{*}}}_{\text {null }}$ is smaller than 1 but larger than 0.95. In this case, more transparency reduces the expected level of output but the effect tends to be trivial.

\section{Conclusion}

In this paper, we develop a theoretical framework that integrates market transparency, risk sharing opportunities, and resource allocations in an open economy under exchange rate risk. The aim of our study is to discuss the economic implications of more transparency in the foreign exchange market. The uncertainty to which the international firm is exposed when it decides on resource allocations between domestic and international markets depends on the observed signal as well as on the information system within which the signal can be interpreted. We characterize the foreign exchange market as more transparent if the signal conveys more precise information about the unknown foreign exchange rate. Thus, more information means that the exchange rate uncertainty is reduced through the disclosure of more reliable information.

We show that the effect of more transparency on the ex-ante allocation of production to domestic and foreign markets depends on the marginal revenue and marginal cost func- 
tions. In particular, more transparency leads to a higher expected level of production if the marginal cost function is concave. More transparency leads to a higher expected level of exports if both the domestic marginal revenue function and the marginal cost function are concave. We also show that more transparency always leads to an increase in the expected profit of firm. Furthermore we demonstrate that more transparency may lead to a higher consumer surplus. Our results thus suggest that more market transparency is potentially beneficial in a Pareto sense.

\section{REFERENCES}

Blackwell, D. (1953). 'Equivalent comparison of experiments', Annals of Mathematics and Statistics, Vol. 24, pp. 265-272.

Broll, U. and Zilcha, I. (1992). 'Exchange rate uncertainty, futures markets and the multinational firm', European Economic Review, Vol. 36, pp. 815-826.

Citanna, A. and Villanacci, A. (2000). 'Incomplete markets, allocative efficiency, and the information revealed by prices', Journal of Economic Theory, Vol. 90, pp. 222-253.

Eckwert, B. and Zilcha, I. (2001). 'The value of information in production economies', Journal of Economic Theory, Vol. 100, pp. 172-186.

Eckwert, B. and Zilcha, I. (2003). 'Incomplete risk sharing arrangements and the value of information', Economic Theory, Vol. 21, pp. 43-58.

Engel, C. and Rogers, J. H. (1996). 'How wide is the border?', American Economic Review, Vol. 86, pp. 1112-1125.

Engel, C. and Rogers, J. H. (2001). 'Violating the law of one price: Should we make a Federal case out of it?', Journal of Money, Credit and Banking, Vol. 33, pp. 1-15.

Green, J. (1981). 'The value of information with sequential futures markets', Econometrica, Vol. 49, pp. 335-358.

Heinemann, F. and Illing, G. (2002). 'Speculative attacks: Unique equilibrium and trans- 
parency', Journal of International Economics, Vol. 58, pp. 429-450.

Hirshleifer, J. (1971). 'The private and social value of information and the reward to incentive activity', American Economic Review, Vol. 61, pp. 561-574.

Hirshleifer, J. (1975). Speculation and equilibrium: information, risk and markets', Quarterly Journal of Economics, Vol. 89, pp. 519-542.

Kawai, M. and Zilcha, I. (1986). 'International trade with forward-futures markets under exchange rate and price uncertainty', Journal of International Economics, Vol. 20, pp. $83-98$.

Kihlstrom, R. E. (1984). A "Bayesian" exposition of Blackwell's theorem on the comparison of experiments', in M. Boyer and R. E. Kihlstrom (eds), Bayesian Models in Economic Theory, Amsterdam, Elsevier, pp. 13-31.

Kim, S. K. (1995). 'Efficiency of an information system in an agency model', Econometrica, Vol. 63, pp. 89-102.

Krebs, T. (2005). 'Fundamentals, information, and international capital flows: A welfare analysis', European Economic Review, Vol. 49, pp. 579-598.

Lehmann, E. L. (1988). 'Comparing location experiments,' Annals of Statistics, Vol. 16, pp. 521-533.

Morris, S. and Shin, H. S. (2002). 'Social value of public information', American Economic Review, Vol. 92, pp. 1521-1534.

Parsley, D. C. and Wei, S. J. (1996). 'Convergence to the law of one price without trade barriers or currency fluctuations', Quarterly Journal of Economics, Vol. 111, pp. 12111236.

Schlee, E. (2001). 'The value of information in efficient risk sharing arrangements', American Economic Review, Vol. 91, pp. 509-524.

Shaked, M. and Shanthikumar, J. G. (1994). Stochastic Orders and their Applications. Boston, Academic Press. 
Sulganik, E. and Zilcha, I. (1997). 'The value of information: The case of signal-dependent opportunity sets', Journal of Economic Dynamics and Control, Vol. 21, pp. 1615-1625.

Thijssen, J. J., Huismann, J. M. and Kort, P. M. (2006). 'The effects of information on strategic investment and welfare', Economic Theory, Vol. 28, pp. 399-424.

Wakker, P. (1988). 'Nonexpected utility as aversion of information', Journal of Behavioral Decision Making, Vol. 1, pp. 169-175.

Wong, K. P. (2003). 'Export flexibility and currency hedging', International Economic Review, Vol. 44, pp. 1295-1312. 